\title{
Long-term Care and the Labor Market
}

\author{
Atsushi Seike \\ Keio University
}

1. The labor market as key

The feasibility of the proposed Public Long-term Care Insurance (the "PLCI") will depend on the amount of long-term care services which could be provided which will in turn depend on the size of the workforce the service providers can take on and sustain. This memorandum will outline the reasons why labor is one of the most important factors in assessing the feasibility of the PLCI.

In the market economy, the labor market is the only source of the necessary workforce. As in the current situation where there is a general difficulty in persuading people to work for long-term care service providers, the only solution would lie in obtaining the necessary care workers in the labor market by offering the right economic incentives.

If the number of care workers is not sufficient, higher wages may have to be offered to attract people into the sector. It is not possible or fair to regard any kind of workforce as being in short supply unless and until wage increase has been considered and implemented (i.e. market price of that labor has been increased), in respect of that workforce.

A clear case which showed a disregard of this important concept is the case of the socalled the "shortage of nurses problem" of several years ago. At that time, the management of many hospitals and doctors in private clinics complained of the shortage of nurses and demanded the government to increase training facilities for nurses or even to allow foreign nurses from developing countries to work in Japan to reduce the shortage. However, there is no evidence of any increase in the wages of nurses over and above the average wage increase observed across the total workforce. This meant in effect that the "shortage of nurses problem" was not a problem of shortage of nurses as such but was merely a reflection that without an increase in the level of wages for nurses, an insufficient number of people wished to become nurses.

The "mobilisation" or "allotment" of workforce is not allowed in the market economy, i.e. workers cannot be allocated to provide specific tasks. Therefore, as care workers can only be obtained through the labor market through the market mechanism, the PLCI will not be able to achieve its purpose without giving serious thought to the conditions which prevail in the labor market.

\section{The cost of providing care workers}

It would be impossible to employ a sufficient number of care workers immediately. In addition, it will be difficult to immediately have highly skilled workers who would provide specialist services as they would require a longer period of training at a high cost. For example, a medical doctor must attend medical school for at least 6 years before becoming eligible to practice.

In this sense, an appreciation of the skill requirements for each kind of long-term care services is important in assessing the availability of care workers in the labor market. The time period necessary for obtaining sufficient numbers of care workers and the necessary wage level to attract people to supply labor for care services will depend on the skill requirements in each kind of care service.

Major services which are expected to be provided by the PLCI are as follows:

(1) Care services provided by certified care workers

(2) Nursing services provided by nurses

(3) Medical treatment or rehabilitation provided by medical doctors

(4)Care management services provided by care managers

Generally speaking, the more complex services such as care management services and medical services require a longer period of time and higher cost of training before people are able to provide those services although it should be noted that there is a certain cost in time 
and training even to train people to provide the most basic services if certain professional standards are to be maintained.

Since an individual can use his/her resources to acquire other kinds of skills rather than care services, this investment by the individual in human capital for care services should have enough return to attract people. Therefore, the difficulty of obtaining care workers depends on the amount of resources sacrificed by individuals i,e, time and money required to train in each kind of care services.

Amongst the different types of care workers, workers of the type whose skills are relatively basic and easy to perform can be employed on relatively low wages without waiting for a long period of time. Eligible workers to provide this kind of service can be recruited from other sectors relatively easily and they can easily move from one employer to another who offer better working conditions. In other words, this type of care workers will be more susceptible to the demand and supply conditions of the labor market and generally their wages.

On the other hand, care workers whose jobs require a longer period of training time and cost cannot be recruited without paying higher wages that would cover at least the time and money cost of human capital investment paid by them. The other aspect of this, however, is that these professionals do tend to stay in their profession as they have invested so much in terms of human capital and wish not to lose it. They are less likely, therefore, to move to another business and their wages may not increase easily even though the labor market as a whole may be tightening.

\section{Allocation of labor}

Of course, care workers in the labor market are not the sole source of supply of longterm care services. For example, family members can provide care services to some extent. In fact, historically, the family has been one of the most important sources of supply for care services for the elderly in Japan.

One of the reasons why long-term care has been provided by family members is that nothing like the proposed PLCI had been introduced before and only a limited source of care services has been available outside of the home. Traditionally; therefore, family members have had to provide care even if they were not willing to do so. In some cases, the elderly also preferred to be taken care of by the family even where outside help was available. In cases where the family members are willing to provide care, the family will be an important ongoing source of care and there should be no problems in them doing so to the extent of their competence.

However, it should be noted that the supply of long-term care by the family can be expensive from both the individual and the social points of view. This is because the productivity in providing care services is lower for family members than for that provided by professional care workers. The family members providing care often sacrifice opportunities to earn wages themselves. The society then loses the insurance premiums and income taxes that could have been levied on their earnings.

Volunteer workers may also be able to provide long-term care services. In fact, many volunteer organisations have started providing various kinds of care services already. However, as in the case of family members providing care, the use of volunteer organisations may have a cost to society.

Volunteer workers also tend to be less dependable than the professionals in the labor market as their availability is not certain. The fact that the provisions of services by them is purely dependent on their goodwill also means that there isn't a real element of choice for the consumers. This means that improvement in the quality of services offered is unlikely to be achieved by market competition.

The other important source of care services may be equipment. Equipment has already been introduced to support care services to a certain extent and an increase in the demand for equipment may induce the manufacturers of the equipment to invest in R \& D in order to progress the technology in the field of care services. In this respect, the labor market mechanism that would increase the wages of care workers when they are in short supply is very important because increases in the wages of care workers is the most powerful incentive for care service providers to introduce as much equipment as possible to replace expensivi labor. In turn, if care service providers introduced more equipment, the incentive for thi 
manufacturers to invest in $\mathrm{R} \& \mathrm{D}$ would increase. Because the Japanese society is projected to suffer labor shortage in the years to come, it is important for us to maximise the use of equipment where equipment would suffice and to use people for services that only human beings can provide. This would apply across a whole range of businesses not just to long-term care services.

Further readings:

Seike A: Development of care system and its methodology (Kaigo shisutemu no kochiku to sono hoho), Quart Soc Security Res 1995; 31(1) 


\title{
How the System Can Be Sustained Politically
}

\author{
Yasunori Sone \\ Keio University
}

If asked to identify the main policy questions facing Japan, for the short run most people would probably mention the monetary system and massive defaults, for the medium term financial and administrative structural reform, and for the long term, the aging society and social security. There would be general agreement on the importance of the social security problem and on what needs to be done from now on. Even those who call for small government and "personal responsibility" haven't gone so far as to call for cuts in social security spending.

At the general level, the various political parties don't differ much in thinking about social security in the context of fiscal restraint, but there are differences in their more specific approaches and a lot has yet to be decided. Moreover, methodologically speaking, economists can make a powerful argument for fiscal constraints, but the sorts of claims made in opposition by the Japan Medical Association (JMA) or people in the welfare field, such as "medical care is a special case," do not have much theoretical basis. Since political decisions have to be made among such competing claims as "agriculture is a special case" and "education is a special case," the old debates about medical care-"equality vs. freemarket" or "fairness vs. efficiency" are not enough, and advocates will have to explain precisely why "medical care is a special case." Here, as well as debating the content of medical policy, we have to think about the government's decision-making system itself. The process of enacting the Public Long-Term-Care Insurance Law provides a good case study.

The Public Long-term Care Insurance Law passed the Diet in December 1997, after revision and supplementary resolutions. Most likely no one believes that the enactment of this law has solved the majority of the care-related problems that Japan faces in its aging society. Even people who are in favor of this system think it is insufficient and predict system overload in the future. Most people seem to view it in terms of setting up an absolute minimum safety net, but opinion is split on the question of whether this really is the minimum.

Naturally, it takes a long time to introduce such a new system, and a lengthy decisionmaking process ensued. We need to look at the various opinions that surfaced and see how the advantages and disadvantages of each proposal were weighed and reconciled. In doing this, we need to distinguish the discussions associated with the formal decision process from the mere expressions of opinion in the mass media and other forums. Here we will concentrate on formal policy making with less attention to public opinion and the media. Note incidentally that although future medical insurance and health policy reforms will not necessarily go through this same process, this case study does reveal the basic pattern of Japanese policy making today, as can also be seen in other policy areas.

It would be a mistake to think that debates about health policy in Japan get started in the legislature, but it would also be wrong to assume that the Ministry of Health and Welfare (MHW) and the JMA just decide everything on their own. To analyze actual decision-making, it is helpful to divide the process into two parts: from initiating a proposal to drafting a bill, and then the formal process of enactment.

A peculiarity of the Japanese policy formation process is that the administrative arm of government is more active in drafting legislation than are the political parties. One can't see what is really going on without looking inside the bureaucracy, but it is possible to get an idea of the various proposals being considered by looking at advisory committees. The JMA and other groups are members of these committees and so can put forward their views and interests there. However, informally, a powerful group like the JMA is also in constant communication with the MHW behind the scenes, and so can learn about ministry thinking and convey its own views quite easily.

Even when a policy direction is decided by a ministry after all these council 
deliberations, it can be changed in the political process. In the case of LTCI, local government opposition resulted in postponing introduction of the bill in the 1996 legislative session. In 1997, the views of the Democratic Party along with the need for some adjustments within the ruling coalition led to a political accommodation. In the end, the bill passed the Lower House in the 1997 regular session, but it was held over in the Upper House until the fall 1997 special session.

We should not disregard the influence of this kind of political horse trading at the end of the process on the actual decision. However, we certainly cannot assume that the key questions were really resolved at this stage-for example, what are the real conflicts of interests, what problems will actually result from implementing LTCI, what difficulties come with taking a social-insurance rather than tax-based approach? The key here is that the basic outlines of the program were not really altered in the political process, but by and large remained as decided by the MHW.

When it comes to future reforms of the medical insurance system, problems with the pension system, and other problems of the aging society, we will inevitably have to depend on non-market (political, administrative) decisions, even if our goal is to introduce market mechanisms. In such cases, it is somewhat unrealistic to treat the government in Japan as a single unit, and we should assume it to be composed of two units, political and executive. In addition, policy decision making is influenced by the contributions of interested parties, including the Medical Association, insurance groups, and welfare groups, as well as public opinion.

Furthermore, unlike the era when the Liberal Democratic Party had a solid majority in the Diet, the decision-making process is further complicated by the need to coordinate interests within the ruling coalition. At times, negotiations with some ruling or minor party that has taken a vague political position, as the Democratic Party of Japan did in 1997, enter into the picture, and the decision is delayed or modified.

What is a "politically sustainable program?" As we have seen, it is necessary to start with a sustainable bill, and then it is a matter of how political parties and interest groups get together in the political process and whether public opinion support can be gained. Clearly, with respect to LTCI, most of the arguments are about things that will happen only in the future, so the debate hasn't really sharpened. As Japan ages, however, the new system will be put into effect, people will be making judgments, complaints will be coming up from practitioners and clients, and LTCI will become a future political focal point. 


\title{
Market Elements in Financing and Delivering Long-term Care
}

\author{
Naohiro Yashiro \\ Sophia University
}

This paper overviews major issues with the Public Long-term Care Insurance (LTCI) Scheme in Japan which is to be introduced in the year 2000. Unlike other public insurance schemes on pension or health, which are mainly based on already-established individual occupational categories, LTCI is newly-established and thus one could have painted an ideal picture on a blank canvas. Nevertheless, the actual outcome is quite complicated, mainly due to a series of political compromises. Thus, let us first draw an ideal fiscal scheme of LTCI and find the way to be back there.

A prominent feature of the LTCI is a mixed nature of the essence of health and pension insurance schemes. Currently, both health and pension insurance schemes are under severe restructuring for meeting with the fiscal pressures with the aging of the population. They have several common problems:

- First, social insurance schemes are divided between those mainly for selfemployed and for wage earners, and the latter are also fragmented by occupational groups. Substantial fiscal transfers are needed mainly for adjusting the different ratios of the elderly between different schemes;

- Second, while the social insurance schemes for self-employed are based on individuals, those for wage earners are on family units i.e. the benefits of dependent spouses are covered by the contributions by the household's head. This causes the inequality of benefits between the families of the spouses with their own earnings and those without. Those benefits to dependent spouses unmatched by the contributions also bring about an "implicit tax" on their working beyond a certain earnings;

- Third, contributions are flat for self-employed while are earnings-related for wage earners which are shared equally between firm and the employees. The different fiscal schemes by employment status and occupations make the pension and health insurance schemes more complicated, leading to the need for fiscal transfers between them.

Thus, an "ideal" social insurance on a blank canvas should have been an uniformed scheme covering all the people in the country regardless of their occupations or employment status, the flat contribution and benefit schedules on an individual base, and no contributions by an employer. The actual outcome of the LTCI scheme, however, is quite complicated, mainly because it is based on the current health insurance schemes. Also, using age as a critical factor in dividing both contributors and beneficiaries makes the scheme more complicated.

For those age 65 and above, it is individually-based with their contributions deducted automatically from their pension benefits. They are also qualified for benefits with a certain eligibility criteria. For those age 40 to 64 , the contributions of both self-employed and wage earners are based on their health insurance schemes. Those for wage earners are family-based and the half of the contributions are paid by the employer. The beneficiaries in this age group are subject to the condition that the cause of being frail should be age-related. Those employed under age 40 are neither contributors nor beneficiaries unlike the cases in other social insurance.

A major issue here is why those who are in need of LTC should not be treated equally regardless of the cause. Also, contributions should also be imposed on those below age 40, as LTCI is not only for frail elderly, but for the family members who actually take care of them.

There are alternative scenarios on the actual implementations:

- First is the case when the basic package of LTC is set to be quite generous. The 
costs for LTC services would rapidly increase with an expansion of demand for visiting home services, and the eligibility criteria is likely to work as de facto quota for LTC services. Then, the middle income class may have to shift to market services, just as a part of the medical services of top quality currently being provided without using health insurance;

- Second is the case when the basic package covered by LTCI is mainly targeted to those who are seriously handicapped away from those who need complementary services to ordinary life. A simple criteria of the expenditures for LTC is based on the "shadow prices" of hospitalization; as the terminal care in hospitals is quite costly, those who are in equivalent status have priorities in LTC. However, the "costs" here should not be solely judged at a point of service provision. Appropriate supply of rehabilitation or precautionary measures could save the life-time LTC costs substantially.

- Third is the ratio of co-payment at the point of serve provision. With the current 10 percent co-payment ratio, the induced-demand effect by the establishment of LTCI should be larger, accounting for subjective needs in LTC services. Ideally, the co-payment ratio should be higher with the waive for those with very low income i.e. the introduction of means-tested in LTCI only for the co-payments.

One of the major purposes for LTCI is to shift the provision of LTC services from the public sector to market. The market for LTC has been under-developed for many reasons: one, most of the services used to be provided by family members with intra-family "implicit contracts" tied with the transfers of incomes and assets between generations; two, the costs of LTC services in welfare programs are financed by general revenues, and are directly paid to the providers, so that beneficiaries are not considered as consumers choosing from alternative service providers.

Establishment of LTC in the framework of social insurance stimulates the better utilization of market:

- First, there is a competition between suppliers towards lowering the costs and/or improving the quality of services, by shifting from the supplier-oriented schemes of public welfare. Consumers subsidized by the LTCI have freedom to choose as in the cases for ordinary services in the market;

- Second, the scale economies for provision of LTC services could be expected by uniting the current fragmented demand by both low and high income peoples into a single large market. Thus, there should be a mechanism that "good suppliers" can expand their business while bad ones to exit from the market. An example is a franchised network organizing independent suppliers which provides uniform qualified services nation-wide under the same brand name;

- Third, the role of government is important not as a controller of the market by regulations but as a supervisor for the market to work efficiently by securing the information on the quality of LTC services provided by various suppliers as well as the protection of consumers. Providing of information for promotional purposes should be widely allowed unlike medical services.

Setting appropriate national fee schedules in LTCI is crucial:

- First, fee-for-service payments have inherent incentives to over-treatment, and bundling of fees needs to be applied more widely in LTCI. Also, the qualification of providers based on their experience should be accounted for;

- Second, unit of care services should not be directly linked to the time spent for that consumer to provide incentives for efficiency. Also, fees should be set for series of care services among which alternative items can be substituted flexibly. A uniform fee schedule for services is necessary to guarantee profits for those suppliers with lower costs.

- Third, costs of using equipment (leased or purchased) should not be treated separately from that of services, so that there can be substitutability between the two, as well as avoiding induced-demand. Inclusion of capital costs for providing a barrier-free home environment in LTCI is questionable, because it increases the value of one's assets and should therefore be financed privately. 
- Finally, the prepaid system like Health Maintenance Organization can be applied in LTC, which provides incentives for preventive measures and rehabilitation of this members to reduce the lifetime costs of LTC.

Use of market mechanism is a key for efficient LTC provision, because LTC is a part of ordinary life of the elderly, and the average elderly in Japan are no longer poor as has been generally perceived. ${ }^{1}$

\section{References:}

1. Yashiro N: The economic position of the elderly in Japan. In: Hurd M, Yashiro N, eds, The Economic Effects of Aging in the United States and Japan, The University of Chicago Press, 1997

Further readings:

Ikegami N: Public long-term care insurance in Japan, JAMA 1997; 278:1310-1314, 1997 